\title{
Research of Micro Lectures Development in Applied Undergraduate Course
}

\author{
Ren Shuyan, *Zhang Cuimin, Qin Yingmei, Song Yanqing \\ Keylaboratory of Information Sensing\&Intelligent Control, \\ Tianjin university of technology and education, \\ Tianjin, China \\ 441998581@qq.com
}

\begin{abstract}
The micro lectures is based on micro teaching video, according to the knowledge of a subject (such as the key points, difficulties and doubts, etc.) or teaching parts (such as learning activities, themes, experiments and tasks), to design video curriculum resources, which can support a variety of learning styles. Practice teaching is an important link in the application of undergraduate teaching, so the application of micro course form to practice teaching can not only enrich the spare time of students, but also optimize the allocation of teaching resources. In the research, micro lectures about Digital Image Processing were developed. The teaching mode based on the micro course was built to integrate teaching resources, accelerate the dissemination of knowledge and understanding, improve the quality of teaching, accelerate the reform of innovative and application-oriented personnel training mode.
\end{abstract}

Keywords—Micro lectures;Practice teaching;Flip class

\section{INTRODUCTION}

Applied undergraduate education is taken as an important type of higher education, and cultivating the applied talents is the goal, so the applied undergraduate education has the commitment to society to cultivate high-quality talents with solid theoretical knowledge, skilled professional skills and a strong ability to innovate the task. Practice teaching[1] is an important way to cultivate practical ability. In order to achieve the goal of training talents, colleges and universities should grasp the theory teaching and practice teaching. Therefore, application-oriented universities[2] must strengthen the practice teaching, achieve the combination of theory and practice. Practice teaching is the most important and key link to cultivate applied talents in the teaching process, in which, students participate in various activities, so they can find the problem. Through the analysis of problems, judgment and reason they can find a way to solve the problem, improve the theoretical and practical ability in the application.

At present, most of the graduates will be able to do the job only after the retraining of the employer, because the theoretical knowledge of college students is out of touch with the actual work and lack of ability to practice. This increases the cost of training a large number of enterprises, so they are not willing to undertake the university graduates and tending to recruit employees with work experience. Applied undergraduate education can meet the needs of social development for talents after strengthening the practice teaching.

\section{PRACTICAL CURRICULUM SYSTEM OF APPLIED UNDERGRADUATE EDUCATION}

The professional practice curriculum is very important to the application oriented undergraduate education. So the design and research of this kind of curriculum also highlight the relationship between the 'practical curriculum' and 'applied undergraduate education. Combined with the construction of strategic emerging industries in Tianjin, we build the following practical curriculum system as shown in Fig.1.

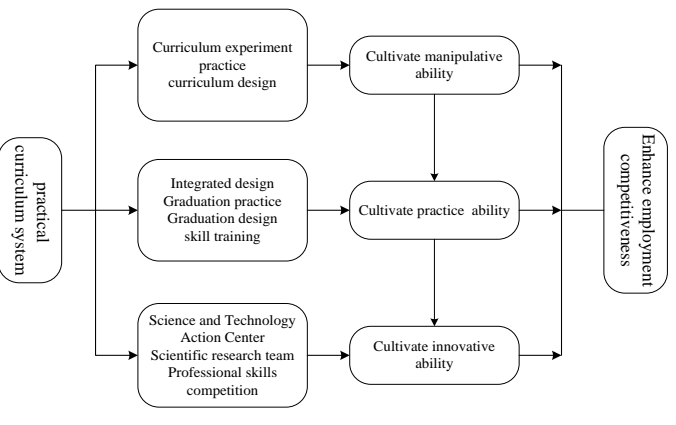

Fig. 1. Practical curriculum system 
The professional practice course would break the traditional teaching mode and the curriculum setting, and pay attention to the cultivation of active thinking, participating in practice and executive ability of students.

\section{MICRO TEACHING}

\section{A. Instructional objective}

If students watch the video from teachers, they do not need to concentrate on like in the classroom, worry about missing important content and teaching, also do not need to worry about following teaching rhythm, and they can learn in a relaxed environment. Students use their own pace to grasp the distribution of each video segment, watch repeatedly, and they can also stop to take notes or think. Even through chat tools to seek help from teacher. After the implementation of flipped class[3], students can use the teaching video, according to their own learning situation to adjust the pace and rhythm of learning, so the autonomous learning ability would be greatly improved.

In the teaching process of flipping class, collaborative interaction between teachers and students is showed in the classroom, which not only cultivates autonomous learning ability of students, but also strengthens the interaction in learning. The role of teachers has been changed from imparting knowledge to learning guidance of students. And teachers have enough time to participate in the interaction of the students, such as answering questions and doubts of students, and participating in the discussion, so most of students may achieve individual guidance.

\section{B. The principle of micro course development}

Micro curriculum is the prerequisite and basis for the realization of flipped class, and micro video is its core resources. Micro curriculum design should be clear, focused, logical, simple, vivid and inspiring. Our research group has selected a difficult and prone error points in teaching to refinement course, according to the content of the course.

The sounds and images of micro lesson video are clear and stable, pronunciation is standard with the appropriate pace and rhythm. And language is full of appeal. Because the video content should be short and straight, in order to achieve good learning effect, teaching design should be novel and interesting, which can fully mobilize the interest and learning enthusiasm of students. In addition to micro lesson video resources, our research group will design the micro courseware according to the video, interactive micro exercises with moderate difficulty, micro reflection, micro feedback, etc.

Watching micro video is just the first link in the flip class. After this link, students will come to the classroom with the difficulties which have not been understood, to resolve them. This link is essential for students to form the correct concept, test the results of independent learning. Our research group conducted reform in the class, changed the traditional teaching mode, only focus on the knowledge to explain, collect the problems from students, encourage them fully in the class discussion, active cooperation, and solve problems together. The success of this link depends on whether the teachers fully understand the students, and fully mobilize their enthusiasm to participate in the discussion, and establish a good habit of collaborative learning.

At the end of class, teachers should layout development practice tasks based on knowledge points to provide students the training opportunities to solve problems in the real situation. Supplement by reflection make students independent discussion and reflection, to promote knowledge and skills further internalized and sublimation.

Practice teaching put the students into the real or virtual reality environment, and the students need to face the specific and realistic problems, let students practice thinking using comprehensive knowledge and, and need to explore new knowledge outside the professional knowledge of college students, in order to solve the problem correctly. This kind of learning mode not only develop the thinking skills of students, but also make students master the professional knowledge more flexible, help to improve learning enthusiasm and learning autonomy of college students.

\section{THE APPLICATION OF MICRO COURSE IN DIGITAL IMAGE PROCESSING}

The course of Digital Image Processing[4] is a hot research direction of extensive computer science, which is the foundation of research in the field of automation and intelligent control, a key subject, a combination of theory and practice, and a course connected principle and application. The basic theory includes image acquisition, image transformation, image enhancement, image restoration, image compression, image segmentation and feature analysis. The use of micro course and flipped class can exchange the roles of teachers and students. Digital Image Processing course is studied autonomously with micro lesson video. While students were watching the video, synchronous exercises had been finished to achieve the effect of image processing. Then they clicked the video to play, learning important and difficult problems one by one, to produce satisfactory works, which will greatly stimulate learning enthusiasm of students. So the kind of micro teaching form can be regarded as one to one teaching mode. 


\section{A. Send micro video}

Teachers complete the micro lesson video recording according with the teaching plan, and concise knowledge structure and logic to show the students clear and complete micro lesson video. Students use the evening study and other spare time to receive micro lesson video released by the teacher, play the focus and difficulty repeatedly until understanding and completion of knowledge learning.

\section{B. Classroom discussion and presentation of image processing results}

On the basis of micro courses, class has changed to a kind of interaction place between the teacher and students, in which, students proposed encountered problem in image processing, and the teacher answers them in time and help them understand deeply to reverse the traditional class and achieve better teaching effect. Fig.1 is the practice result of the student in the class. Students can use a very short time to master a lot of relevant knowledge, and verify them in practice, so their knowledge and ability would be increased rapidly.
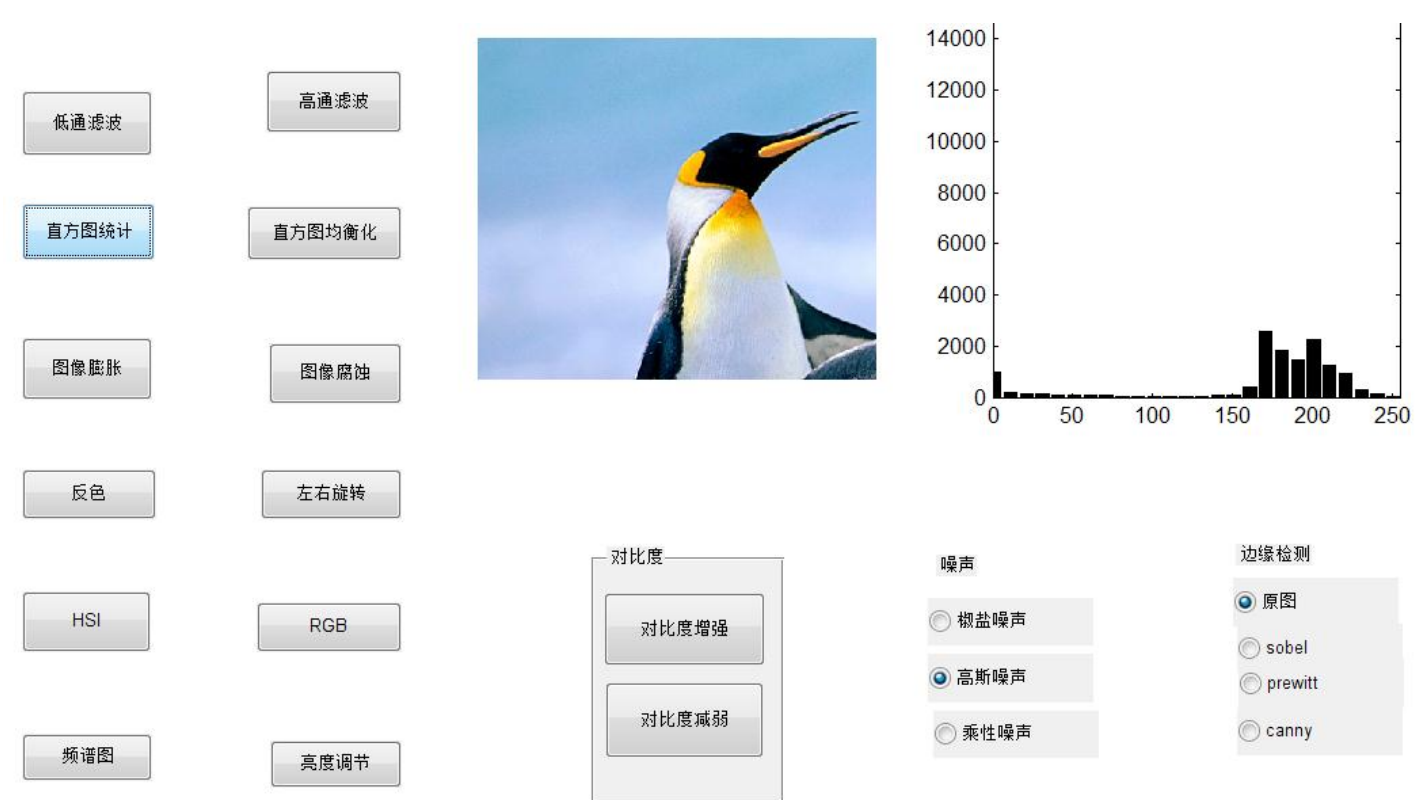

\section{右旅转}
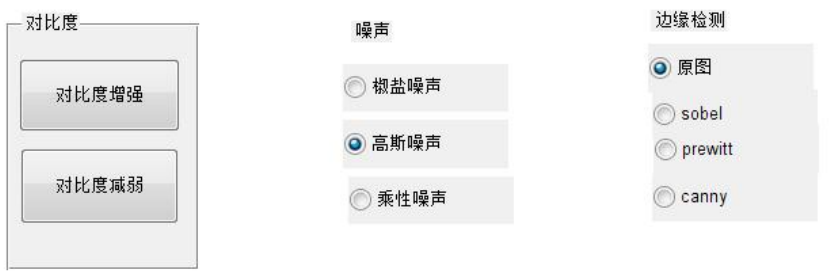

Fig. 2. Results of image processing

\section{SUMMARY}

Flipping class has opened a new mode of teaching, which has become an important part of autonomous learning. Flipping class can also achieve the integration of teaching resources and provide students adequate time to understand and digest knowledge. It is vital to improve the teaching quality and speed up the reform for the talents training mode of application and innovation type.

\section{ACKNOWLEDGMENT}

This research was financially supported by the education reform project of TUTE (JGZ2015-03) .

\section{REFERENCES}

[1] [1] Zhang chuang, Study on Practical teaching in Practical Tertiary Education, Nanchang University, 2008.

[2] [2] Jin xinxin, Zhang daohua, Meng li. The Research on Micro-lesson "Image Processing”Flipped Classroom Teaching Design, Journal of Shaoguan University Natural Science. Vol36(4) (2015) 78-90.

[3] [3] Gu yongan. On the basis of the establishment of teaching quality standards in application oriented Universities Requirement, Chinese University Teaching, No.6 (2010):12-16.

[4] [4] Yang qing, Xu Yan and Wang Shaohua. The Matlab application of digital image processing in CAI, China Electric Power Education, No.10(2013):115-116.

The education reform project of TUTE (JGZ2015-03) 